\title{
Estimate of the Crystallite Size for Nanocrystalline AISI 316L Stainless Steel and Armco Iron Processed by Hydrostatic Extrusion Using Variable Energy Positron Beam
}

\author{
M. SARneK ${ }^{a, *}$, E. DryzeK ${ }^{b}$, P. HorodeK ${ }^{b, c}$ And W. PAChla ${ }^{d}$ \\ ${ }^{a}$ Cracow University of Economics, Rakowicka 27, 31-510 Kraków, Poland \\ ${ }^{b}$ Institute of Nuclear Physics, Polish Academy of Sciences, E. Radzikowskiego 152, 31-342 Kraków, Poland \\ ${ }^{c}$ Joint Institute for Nuclear Research, 6 Joliot Curie Str., 141980 Dubna, Russia \\ ${ }^{d}$ Institute of High Pressure Physics, Polish Academy of Sciences (Unipress), \\ Sokołowska 29, 01-142 Warszawa, Poland
}

\begin{abstract}
The paper presents the results of research of nanocrystalline AISI 316L type stainless steel and nanocrystalline Armco pure iron processed by severe plastic deformation using hydrostatic extrusion method. Surface and subsurface of the steel samples extruded at different pressure were investigated using variable energy positron beam. It enabled us to determine the positron diffusion length and compare its values with those for annealed AISI 304 stainless steel. Furthermore positron lifetime and microhardness were measured for all the samples and X-ray diffraction was used to estimate the crystallite size.
\end{abstract}

DOI: 10.12693/APhysPolA.132.1598

PACS/topics: stainless steel, Armco iron, plastic deformation, hydrostatic extrusion, variable energy positron beam, X-ray diffraction

\section{Introduction}

The dynamic development of modern industries depends on the improvement of structural materials. AISI 316L type austenitic stainless steel is common engineering material widely used as structural material since it shows high resistance to corrosion and oxidation and good formability. Thanks to the use of severe plastic deformation method AISI 316L steel with nanocrystalline grains was obtained. There are proposed other methods of grain refinement based for example on reversion of deformation induced martensite [1]. The transformation was also studied using positron annihilation techniques $[2,3]$.

Materials exposed to severe deformation are characterized by high strength and significantly better plasticity than materials reinforced in a conventional method. In addition, in the case of metals, the grain refinement to nanocrystalline range by cumulative deformation processing causes that these materials exhibit from 3 to 8 times higher hardness in comparison to microcrystalline materials $[4,5]$.

The positron annihilation techniques are well-known experimental methods used for studies of defects in crystalline matter [6]. After thermalization a positron implanted into a metallic system annihilates with an electron emitting two gamma photons. Before annihilation positrons can be localized in regions of lower electron density in comparison to a perfect crystal lattice, i.e., open

*corresponding author; e-mail: sarnekm@uek.krakow.pl volume defects. This is reflected in the Doppler broadening (DB) of the positron annihilation line characterized by the line shape parameters such as the $S$-parameter. Annihilation of positrons trapped in open volume defects causes narrowing of the annihilation line and increase of the $S$-parameter. The positron lifetime (LT), it means the time between emission of a positron from a radioactive source and detection of annihilation photons, depends on electron density. The lifetime is longer for positrons trapped in open volume defects i.e., vacancies, vacancy agglomerates and dislocations than for positrons in a perfect crystal lattice.

In the case of high defect density due to saturation of positron trapping in defects conventional methods of positron annihilation spectroscopy cannot yield information on defect density. Application of variable energy positron (VEP) beam allows us to obtain the values of positron diffusion length and together with positron lifetime results may give information on the defect types and densities [7].

The purpose of the study was checking the usefulness of the VEP method in studies of nanocrystalline materials such as AISI 316L stainless steel and determining the influence of the extrusion parameters on the values of positron diffusion length. The X-ray diffraction was used as a complementary method to estimate the crystallite size.

\section{Experimental details}

The investigated material was stainless steel AISI 316L processed by hydrostatic extrusion (HE) [8]. Its chemical composition is shown in Table I. Armco pure iron, with 
an iron content of minimum $99.85 \%$, without the addition of alloying elements and with all natural impurities largely removed, was prepared using the same method as AISI 316L. Due to the low carbon content (0.01\%), the microstructure consists of pure ferrite.

TABLE I

The chemical composition of the AISI 316L austenitic stainless steel [wt\%].

\begin{tabular}{l|c|c|c|c|c|c|c|c|c|c|c}
\hline \hline $\mathrm{Cr}$ & $\mathrm{Ni}$ & $\mathrm{Mn}$ & $\mathrm{Si}$ & $\mathrm{Cu}$ & $\mathrm{Mo}$ & $\mathrm{Co}$ & $\mathrm{N}$ & $\mathrm{P}$ & $\mathrm{S}$ & $\mathrm{C}$ & $\mathrm{Fe}$ \\
\hline
\end{tabular}

\begin{tabular}{l|l|l|l|l|l|l|l|l|l|l|l|l|l|}
\hline 16.87 & 10.00 & 1.55 & 0.72 & 0.53 & 2.02 & 0.110 & 0.059 & 0.030 & 0.030 & 0.014 & bal.
\end{tabular}

Billets for hydrostatic extrusion were machined to round rods of diameter $25.9 \mathrm{~mm}$ and $19.9 \mathrm{~mm}$ for AISI 316L and Armco iron, respectively. The billets were cold hydrostatically extruded in one pass at different extrusion pressures. In consequence, the rods of diameter $15.95 \mathrm{~mm}$ and $7.94 \mathrm{~mm}$ were obtained for AISI 316L and Armco iron, respectively. Then they were cut to get discs samples of $1.3 \mathrm{~mm}$ and $1.7 \mathrm{~mm}$ in height, for AISI 316L and Armco iron, respectively. More details are shown in Table II.

TABLE II

Parameters of the hydrostatic extrusion process.

\begin{tabular}{c|c|c|c|c}
\hline \hline Material & Sample & $\begin{array}{c}\text { Extrusion } \\
\text { pressure }\end{array}$ & $R^{a}$ & $\begin{array}{c}\text { Extrusion } \\
\text { speed }\end{array}$ \\
\hline 316L & 71 & $1020 \mathrm{MPa}$ & 2.64 & $6.1 \mathrm{~cm} / \mathrm{s}$ \\
$316 \mathrm{~L}$ & 72 & $1030 \mathrm{MPa}$ & 2.64 & $6.1 \mathrm{~cm} / \mathrm{s}$ \\
Armco & $14 \mathrm{~F}$ & $1200 \mathrm{MPa}$ & 6.28 & $10.7 \mathrm{~cm} / \mathrm{s}$ \\
\hline
\end{tabular}

${ }^{a}$ Reduction ratio $R$ - the ratio of the material crosssection surface areas before and after the extrusion.

The hydrostatic extrusion was performed at Unipress Hydrostatic Extrusion Press, with the working chamber diameters of $40 \mathrm{~mm}$ (AISI 316L) and $31 \mathrm{~mm}$ (Armco iron) through the die angle $2 \alpha=45^{\circ}$. The extruded products were cooled with cold running water immediately after they exceeded the extrusion die.

In order to determine the size of crystallites and lattice strain the X-ray diffraction was performed for as-received samples in Philips X-Pert diffractometer using $\mathrm{Cu} K_{\alpha}$ radiation. Results revealed peaks of $\gamma$-austenite for AISI 316L and $\alpha$-ferrite for Armco iron (see Fig. 1).

In order to determine the values of the positron diffusion length, VEP beam at Joint Institute of Nuclear Research in Dubna was used [9]. The positrons emitted from ${ }^{22} \mathrm{Na}$ source of $30 \mathrm{mCi}$ activity were moderated onto frozen $\mathrm{Ne}(7 \mathrm{~K})$. The vacuum conditions were on the level of $10^{-9}$ Torr. Then, they were accelerated to the demanded energy in the range between $50 \mathrm{eV}$ and $35 \mathrm{keV}$ and in the form of a beam of $5 \mathrm{~mm}$ diameter and intensity of $10^{6} \mathrm{e}^{+} / \mathrm{s}$ implanted into the samples. Gamma quanta coming from the annihilation process $(511 \mathrm{keV})$ were registered by the Doppler broadening of annihilation line (DB) spectrometer with $1.2 \mathrm{keV}$ energy resolution interpolated to $511 \mathrm{keV}$.

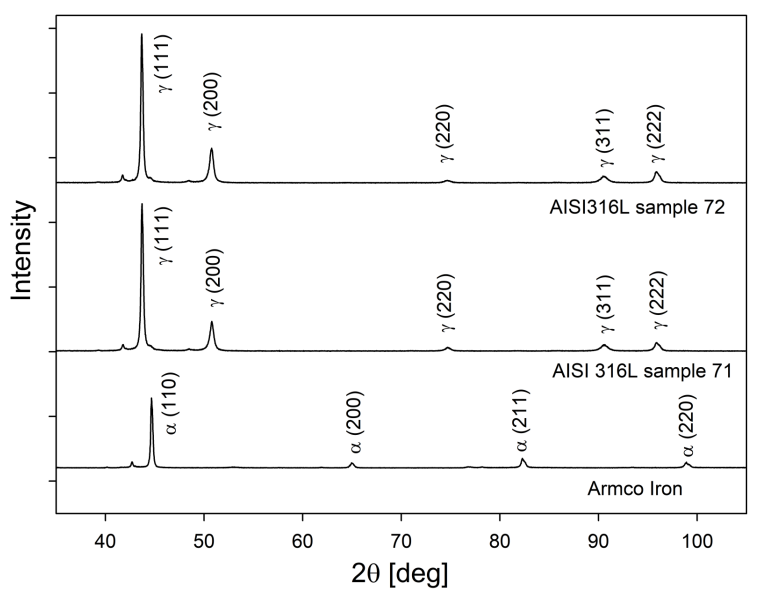

Fig. 1. X-ray pattern of the initial samples after hydrostatic extrusion for AISI 316L and Armco iron.

The positron lifetime spectra of more than $1.5 \times 10^{6}$ counts were measured using a fast-fast spectrometer with $\mathrm{BaF}_{2}$ scintillators. The time resolution of the system was 280 ps. The positron source containing ${ }^{22} \mathrm{Na}$ isotope enveloped in a $7 \mu \mathrm{m}$ thick kapton foil was sandwiched between AISI 316L samples. All the obtained spectra were analyzed using the LT code [10]. The microhardness was measured with the Vickers indenter under $100 \mathrm{G}$ (HV0.1) using a Zeiss-Neophot 21 microscope.

\section{Results and discussion}

The hydrostatic extrusion method may not only lead to a reduction in the crystallite size to nanometric size but also causes an increase in the lattice strain [11, 12]. The reduced crystallite size, the lattice strain and instrumental effects account for the total broadening of XRD peaks. When the crystallites of a material are small (i.e. less than $1000 \AA$ ) they have too small number of parallel diffraction planes and eventually they produce broadened diffraction peaks instead of sharp peaks.

For Arco iron and AISI 316L samples the WilliamsonHall method was used in order to determine crystallite size and estimate lattice strain [13-15]. According to Willson [16], the broadening may be expressed by the relation:

$$
B=\frac{K \lambda}{D \cos \theta}+\eta \tan \theta
$$

where $B$ is the broadening due to small crystallite size and lattice strain, $K$ - a constant whose value depends on a particle shape and usually taken as 1 [17], $D$ is the crystallite size in $\mathrm{nm}$ and $\theta$ is the Bragg angle, $\lambda$ is the wavelength of incident X-ray beam in $\mathrm{nm}$ and its value in experiment was $0.1540530 \mathrm{~nm}$ for $K_{\alpha 1}$ line and $0.1544310 \mathrm{~nm}$ for $K_{\alpha 2}$ line, $\eta$ is a lattice strain. The Williamson-Hall method implemented in PanAlytical HighScore Plus program was used. The results are shown in Table III. 
TABLE III

Data on crystallite size estimation, lattice strain, positron lifetime and microhardness values for Armco iron and AISI 316L.

\begin{tabular}{c|c|c|c|c|c}
\hline \hline \multirow{2}{*}{ Material } & \multirow{2}{*}{ Sample } & \multicolumn{2}{|c|}{$\begin{array}{c}\text { Williamson-Hall method } \\
\text { (HighScore Plus) }\end{array}$} & $\begin{array}{c}\text { Positron } \\
\text { lifetime } \\
{[\mathrm{ps}]}\end{array}$ & $\begin{array}{c}\text { Microhardness } \\
\text { HV0.1 }\end{array}$ \\
\cline { 3 - 4 } & & $D[\mathrm{~nm}]$ & $\eta[\%]$ & $153 \pm 1$ & $213 \pm 10$ \\
\hline Armco & $14 \mathrm{~F}$ & $107.53 \pm 7.11$ & $0.16 \pm 0.02$ & $15 \pm 1$ \\
316L & 71 & $71.94 \pm 5.98$ & $0.33 \pm 0.03$ & $161 \pm 1$ & $385 \pm 10$ \\
316L & 72 & $93.46 \pm 8.05$ & $0.34 \pm 0.04$ & $158 \pm 1$ & $305 \pm 10$
\end{tabular}

X-ray diffraction studies have shown that, due to the cold plastic deformation using hydrostatic extrusion method, materials with nanometric crystallites have been obtained. The results are similar to reported in the literature for nanocrystalline iron obtained by strong deformation methods $[11,18,19]$. For the steel under investigation, the reached crystallite sizes can be compared to the dimensions of the twins observed with the TEM reported in [12].

The dependences of the $S$-parameter on positron implantation energy (bottom axis) and mean implantation depth (top axis) for the reference AISI 304 stainless steel annealed at $600^{\circ} \mathrm{C}$ for $1 \mathrm{~h}$ and nanocrystalline samples of AISI 316L are presented in Fig. 2. The mean implantation depth $z$ was estimated using the formula [20]:

$$
\bar{z}=\frac{A E^{n}}{\rho},
$$

where $E$ is positron energy in $\mathrm{keV}, A$ and $n$ are the Makhov parameters. Solid black lines represent the best fit using VEPFIT code [21] with parameters $A=$ $2.62 \mu \mathrm{g} \mathrm{cm}^{-2} \mathrm{keV}^{-n}, \quad n=1.692, m=1.766, \rho=$ $7.87 \mathrm{~g} / \mathrm{cm}^{3}$ for iron [22].

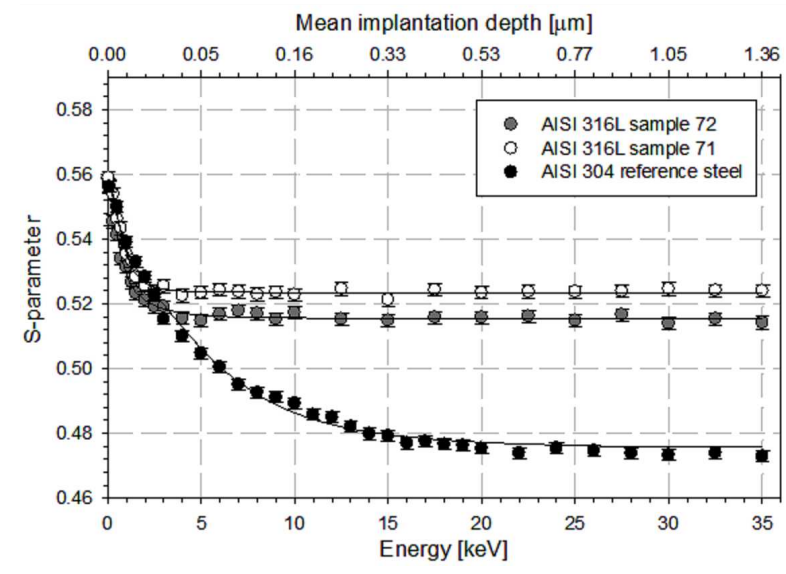

Fig. 2. The dependences of the $S$-parameter on the incident positron energy for the reference AISI 304 and for AISI 316L for 71 and 72 nanocrystalline samples. Solid black lines represent the best fits using VEPFIT code.

The value of the $S$-parameter decreases with increasing incident energy, reaching saturation at approximately $3 \mathrm{keV}$ for $316 \mathrm{~L}$ and $22 \mathrm{keV}$ for the reference sample. It means that in the case of 72 sample positrons from the depth of $13.4 \mathrm{~nm}$ does not came back to the surface. The value of the $S$-parameter in bulk are $S_{\text {bulk }}=0.5235 \pm$ 0.0002 for 71 sample and $S_{b u l k}=0.5155 \pm 0.0003$ for 72 sample. For reference sample $S_{b u l k}=0.4771 \pm 0.0002$. Higher values for the $S$-parameter saturation can be associated with increased concentration of defects. The positron diffusion length $L_{+}$obtained for the reference sample was $79.4 \pm 1.0 \mathrm{~nm}$, which corresponds to the values presented in the literature [23]. For the samples 71 and 72 of the AISI $316 \mathrm{~L}$ steel $L_{+}$was equal to $3.3 \pm 0.4 \mathrm{~nm}$ and $13.4 \pm 2.0 \mathrm{~nm}$, respectively.

Assuming that positrons are localized in defects which are associated with dislocations we can relate the mean value of the positron diffusion length $L_{+}$with dislocation density using the formula:

$$
\rho=\frac{1}{\mu \tau_{b u l k}}\left(\left(\frac{L_{+r e f}}{L_{+}}\right)^{2}-1\right),
$$

where $m$ is the coefficient of positrons trapping rate in dislocations for iron which is equal to $0.51 \times$ $10^{-4} \mathrm{~m}^{2} / \mathrm{s}$ [24]. As for AISI 316L steel, the value of this coefficient was not found in the literature, that is why we used for the calculations the value for $\mathrm{Cr}-\mathrm{Mo}^{-}$ $\mathrm{V}$ low-ferritic steel $0.36 \times 10^{-4} \mathrm{~m}^{2} / \mathrm{s}[25]$. The value of positron lifetime $\tau_{\text {bulk }}$ was equal to $119 \mathrm{ps}$.

Using this from formula (3) we can calculate the density of dislocation. The result is $1.34 \pm 0.1 \times 10^{1} 7 \mathrm{~m}^{-2}$ for the sample 71 and $7.9 \pm 0.8 \times 10^{15} \mathrm{~m}^{-2}$ for the sample 72 . While the value obtained for sample 72 is comparable, for example, to that obtained for nickel deformed by extrusion using equal channel angular pressing method at room temperature [7] the value obtained for sample 71 seems to be particularly high at very low diffusion length. Moreover the smaller crystallite size and higher defect concentration indicated by a higher value of the $S$-parameter, positron lifetime, and shorter positron diffusion length are accompanied by a similar difference concerning microhardness values given in Table III.

The interesting fact is that difference $10 \mathrm{MPa}$ is practically negligible. Large differences both in annihilation parameters and in microhardness values may result from the fact that samples could have been cut from different places of the product after extrusion, i.e. closer to front of the rod extruded form the conical nose of the billet (increasing reduction ratio $R$ ) or from cylindrical portion of the billet (constant extrusion ratio $R$ ).

\section{Conclusions}

X-ray diffraction studies have shown that, due to the cold plastic deformation using hydrostatic extrusion method, materials with nanometric crystallites have been obtained. The defect concentration in the material is so large that all positrons are localized in these defects (saturation trapping of positrons) and conventional methods such as lifetime spectroscopy or the Doppler broadening method do not give information about concentration. However, experiment using a variable positron beam al- 
lows us to determine the positron diffusion length in samples that depends on the concentration of defects localizing positrons. It was found that one of the AISI 316L samples exhibited much lower positron diffusion length indicating higher defect concentration. It seems that samples showing different annihilation parameters and microhardness values were cut from different places of the product after extrusion, one belonging to conical front of the billet (i.e. fabricated with smaller strain) and the other belonging to cylindrical part of the billet (i.e. fabricated with higher strain). It can therefore be assumed that this method gives interesting results for nanocrystalline materials with high defect concentrations.

\section{References}

[1] A. Di Schino, I. Salvatori, J.M. Kenny, J. Mater. Sci. 37, 4561 (2002).

[2] E. Dryzek, M. Sarnek, M. Wróbel, J. Mater. Sci. 49, 8449 (2014).

[3] E. Dryzek, M. Sarnek, K. Siemek, Nukleonika 58, 213 (2013).

[4] J.P. Hirth, J. Lothe, Theory of Dislocations, Wiley, New York 1982.

[5] R.S. Averback, Z. Phys. D 26, 84 (1993).

[6] R. Krause-Rehberg, H.S. Leipner, Positron Annihilation in Semiconductors, Vol. 127, Solid-State Sciences, Springer, Berlin 1999.

[7] R. Krause-Rehberg, V. Bondarenko, E. Thiele, R. Klemm, N. Schell, Nucl. Instrum. Methods Phys. Res. B 240, 719 (2005).

[8] W. Pachla, J. Skiba, M. Kulczyk, S. Przybysz, M. Przybysz, M. Wróblewska, R. Diduszko, R. Stępniak, J. Bajorek, M. Radomski, W. Fąfara, Mater. Sci. Eng. A 615, 116 (2014).

[9] P. Horodek, A.G. Kobets, I.N. Meshkov, A.A. Sidorin, O.S. Orlov, Nukleonika 60, 725 (2015).
[10] J. Kansy, Nucl. Instrum. Methods Phys. Res. A 374, 235 (1996).

[11] H. Garbacz, M. Lewandowska, W. Pachla, K.J. Kurzydłowski, J. Microsc. 223, 272 (2006).

[12] A.T. Krawczyńska, M. Lewandowska, K.J. Kurzydłowski, SSP 140, 173 (2008).

[13] P. Scherrer, Nach. Goettinger Gesell., Zsigmondy's Kolloidchemie, 3rd ed., 1918.

[14] B.R. Rehani, P.B. Joshi, K.N. Lad, A. Pratap, IJPAP 44, 157 (2006).

[15] D. Oleszak, A. Olszyna, Kompozyty (Composites) 4, 284 (2004) (in Polish).

[16] A.J.C. Willson, X-ray Optics, Methuen, London 1949.

[17] B.E. Warren, X-ray Diffraction, Dover, New York 1969.

[18] K.A. Darling, B.K. VanLeeuwen, J.E. Semones, C.C. Koch, R.O. Scattergood, L.J. Kecskes, S.N. Mathaudhu, Mater. Sci. Eng. A 528, 4365 (2011).

[19] H. Natter, M. Schmelzer, M.S. Löffler, C.E. Krill, A. Fitch, R. Hempelmann, J. Phys. Chem. B 104, 2467 (2000)

[20] S. Valkealahti, R.M. Nieminen, Appl. Phys. A 32, 95 (1983).

[21] A. Van Veen, H. Schut, M. Clement, J.M.M. De Nijs, A. Kruseman, M.R. Ijpma, Appl. Surf. Sci. 85, 216 (1995).

[22] J. Dryzek, P. Horodek, Nucl. Instrum. Methods Phys. Res. B 266, 4000 (2008).

[23] Y.C. Wu, Y.C. Jean, Phys. Status Solidi C 4, 3506 (2010).

[24] Y.K. Park, J.T. Waber, M. Meshii, C.L. Snead Jr., C.G. Park, Phys. Rev. B 34, 823 (1986).

[25] J. Cizek, I. Procházka, J. Koccaroník, E. Keilová, Phys. Status Solidi A 178, 651 (2000). 